\title{
Plagiarism: Ke Garne ?
}

\author{
Academic fraud must have consequences
}

\begin{abstract}
A
few days ago, as we were rushing to press with an issue that has been plagued by unforeseeable delays, we found that one of our articles contained plagiarized material.

"Tut-tut," you say. "A purloined phrase... an undocumented source? Where's the harm? dy does it!"

Purloined phrase? Not quite. One of the sources cited for apparently minor points was in fact looted: page after page was lifted verbatim, along with the major conclusions, which were simply grafted onto the article that we were about to publish.

And where's the harm? Well, forgive our petulance, but we wasted hours and hours of our time on a 36-page manuscript, reviewing, revising, and eventually exposing it. The cover, contents, and layout of this entire issue had to be redone. All of which is trivial compared to the fiasco narrowly averted. Had we actually published the article, we would have directly injured the original author (and his publisher), whose intellectual property and professional stock-in-trade were stolen; we would have brought disrepute on ourselves and our journal; and we would have been exposed to legal and financial repercussions, including the
\end{abstract} danger of diminished support from those on whom the ultimate success of the journal depends.

An even greater loss is now incurred by us all through the thwarted dissemination of important information and ideas. The article in question applied findings pertinent to one group of endangered fish, whose genetic diversity and is threatened by captive breeding and realease, and proposed that the same might be true of a group of Himalayan fish. Such applications of published scholarly research represent the best-case scenario for our journal, our readers, and our society; yet we are no choice but to withdraw the article.

Everybody does it? Academic dishonesty is certainly rampant, and probably nowhere more than in Nepal, where political, commercial, and legal corruption have a solid schooling in our educational system. All the more reason to take a stand and do something about it.

First of all, we will review and clarify our guidelines for contributors, in order to minimize the likelihood of inadvertent plagiarism. Second, we

It wasn't your typical fish story. This wasn't a fisherman exaggerating the size of the one that got away - it was a case of massive plagiarism. Fortunately, HJ S editors caught it before the story went to print, but we paid a price in time, money, and goodwill. Now we have to think seriously about what we can do to protect ourselves from intellectual dishonesty. We invite your suggestions and your collaboration. are considering a policy of public exposure of all those who use or attempt to use the Himalayan Journal of Sciences to perpetrate intellecual fraud. Third, we are taking steps to organize a symposium of publishers, academics, and legal experts in order to develop strategies for dealing with a problem that undermines our institutions and threatens our future, as well as other forms of scientific misconduct.

We invite your input and collaboration. 